\title{
The Scope of Support of Toolkits in the Smartphone Industry
}

\author{
Jing-Ming SHIU ${ }^{\mathrm{a}}$
}

\begin{abstract}
Companies that develop products with IC (Integrated Circuit) chipsets use toolkits provided by semiconductor suppliers to implement their own series of trial-and-error experiments ranging from concept creation to problem-solving in product developments. According to von Hippel (2001), toolkits have the following elements: (a) learning by doing via trial-and-error, (b) module libraries, (c) solution space, (d) user-friendly, and (e) translating user designs for production. This study defines (b) and (c) as the scope of support for toolkits and compares this scope for Android smartphone manufacturers (Samsung, Huawei, Vivo, and OPPO), which were provided by semiconductor suppliers (Qualcomm and Mediatek) in the 2010s. As a result, this study found that the scope of support of Mediatek's toolkit is broader than Qualcomm's. Compared to Samsung, Huawei, Vivo, and OPPO tended to adopt Mediatek's toolkit to benefit from the broader scope of support in their Android smartphone developments.
\end{abstract}

Keywords: the scope of support of toolkit, product development, semiconductor supplier, Android smartphone

a) Department of Business Administration, National Cheng Kung University, No.1, University Road, Tainan City 701, Taiwan (R.O.C.), jingmingshiu@gmail.com

A version of this paper was presented at the ABAS Conference 2016 Autumn (Shiu, 2016).

(C) 2017 Jing-Ming Shiu. This is an Open Access article distributed under the terms of the Creative Commons Attribution License, which permits unrestricted reuse, distribution, and reproduction in any medium, provided the original work is properly cited. 


\section{Introduction}

In the Information and Communications Technology (ICT) industry, companies use IC chipsets to develop their products while getting technical support from semiconductor suppliers. Semiconductor suppliers (e.g., Qualcomm, Texas Instrument, Mediatek, etc.) usually determine what sort of technical support they should provide by judging the product development capabilities of companies (Yasumoto \& Shiu, 2007).

One way to provide technical support to companies is by supplying "toolkits." By using toolkits from semiconductor suppliers, companies can conduct their own series of trial-and-error experiments, ranging from concept creation to problem-solving in product developments. Furthermore, companies can use toolkits to develop their own IC chipsets for their products. ${ }^{1}$

Von Hippel (2001) first indicated toolkits have the following elements: (a) learning by doing via trial-and-error, (b) module libraries, (c) solution space, (d) user-friendly, and (e) translating user designs for production. Afterward, the (b) module libraries and (c) solution space are most attracted and discussed in many researches relevant to toolkits. ${ }^{2}$

As defined in von Hippel (2001), module libraries are where users can proceed to develop their own desired style by adding and

1 For example, Cadence Design Systems, Inc. specializes in providing toolkit for those companies who develop their own IC chipsets (https://www.cadence.com/content/cadence-www/global/zh_TW/home. html). In 2000, approximately 15 billion US dollars worth of semiconductors were developed and manufactured using toolkits (Thomke \& von Hippel, 2002).

2 For example, the "toolkit's scope" of Prügl and Schreier (2006) is used as a concept similar to (b) module libraries. The "toolkit's spectrum" of Franke and Piller (2003), the "solution space" of Franke and Piller (2004), and the "design freedom" of Bergvall-Kåreborn, Björn, and Chincholle (2011) and Wang and Li (2013) are treated as being conceptually similar to (c) solution space. 
subtracting from a standard database. Solution space is where users are allowed to manipulate and combine relatively basic and general-purpose building blocks and operations. By assimilating module libraries and solution space, users can also understand the design availability and limitation in their product developments. This study defines these two elements as the scope of support of a toolkit.

\section{Sample}

Past researches in the semiconductor industry have dealt with a variety of analysis objects. For example, Weber (2002) and Min (2016) investigated the division of labor between semiconductor suppliers and vendors who provide materials and equipment to semiconductor suppliers for the production of semiconductors. von Hippel (2001) focused on the division of labor shaping by semiconductor suppliers and their users, who may tend to design IC chipsets by themselves. This study analyzes the interfirm relation between the semiconductor suppliers and the companies who use IC chipsets to develop products.

In the first quarter of 2015, Qualcomm had 61\% market share of worldwide baseband chipset $^{3}$ sales for Android smartphones. This was followed by Mediatek at 18\% and Spreadtrum's at $7 \% .{ }^{4}$ This study focuses on Qualcomm's and Mediatek's relations with Android smartphone manufacturers from 2013 to 2016.

According to IDC, 5 the top five smartphone manufacturers worldwide between the third quarter of 2015 and the second quarter of 2016 were Samsung (22.58\%), Apple (14.78\%), and Chinese firms

3 https://en.wikipedia.org/wiki/Baseband_processor

4 http://www.prnewswire.com/news-releases/mediatek-captures-doubledigit-share-in-lte-basebands-in-q1-2015-says-strategy-analytics-3001077 05.html

5 http://www.idc.com/prodserv/smartphone-market-share.jsp 
(Huawei: 8.38\%, Vivo: 4.05\%, OPPO: 3.43\%). As Apple develops their own iOS for their smartphones, this study chose Android smartphone manufacturers (Samsung, Huawei, Vivo, and OPPO) as companies that use Qualcomm's and Mediatek's IC chipsets.

Of these four, Huawei, Vivo, and OPPO are new entrants who are catching up with Korean and Taiwanese Android smartphone manufacturers (Lee, 2005; Mu \& Lee, 2005). Android smartphone manufacturers compete in the field of product development (Shiu $\&$ Yasumoto, 2016), and their relations with semiconductor suppliers will contribute to their product development advantages.

This study used the http://pdadb.net database to calculate the number of Qualcomm's and Mediatek's IC chipsets that were used in the new Android smartphone developments of Samsung, Huawei, Vivo, and OPPO. ${ }^{6}$ Although Samsung and Huawei also used their own IC chipsets and Chinese semiconductor suppliers in their Android smartphone developments, this study only focuses on the number of Qualcomm's and Mediatek's IC chipsets they adopted. As shown in Figure 1, between 2013 and 2016, Samsung, Huawei, Vivo, and OPPO developed 30, 31, 26, and 27 new Android smartphones, respectively. ${ }^{7}$ The number of Qualcomm IC chipsets adopted in Samsung's, Huawei's, Vivo's, and OPPO's Android smartphone

${ }^{6}$ Alcacer and Oxley (2014) also used this database to analyze mobile phone manufacturers' product development capabilities.

7 Whether companies develop a "new" model or derived one can be judged by the technological newness in the product developments. In Android smartphone developments, the technological newness results in the integration between IC chipsets and Android operation system. Since Google releases new Android operation system every year, Android smartphone manufacturers have to integrate IC chipsets with the new Android operation system (e.g., drivers porting, testing, etc.). In this sense, the Android smartphone can be regarded as a "new" model with the latest of Android operation system version. Therefore, by judging the quantity of different series number of Qualcomm's and Mediatek's IC chipsets adopted in Samsung, Huawei, Vivo, OPPO Android smartphones every year, this study could speculate the number of new Android smartphones which were developed by Samsung, Huawei, Vivo, OPPO. 


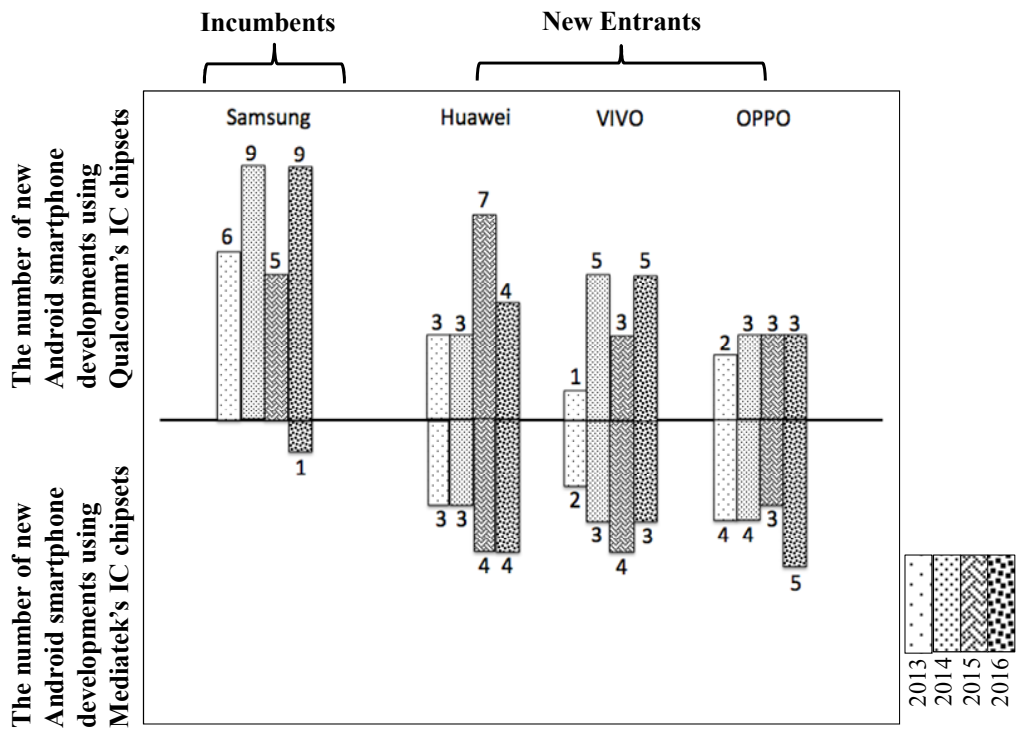

Figure 1. The number of IC chipsets adopted in Samsung's, Huawei's, Vivo's and OPPO's Android smartphone developments.

Source: Author's analysis

developments is $96.67 \%, 54.84 \%, \quad 53.84 \%$, and $40.74 \%$, respectively. That is to say, Samsung tended to use Qualcomm's IC chipsets almost exclusively in their Android smartphone developments; Huawei, Vivo, and OPPO adopted both Qualcomm's and Mediatek's IC chipsets by a certain percentage.

\section{Results}

To reveal the scope of support of Qualcomm's and Mediatek's toolkits, approximately seven hours of interviews were conducted with two engineers each from Qualcomm and Mediatek in October 
2014. On November 16, 2016, this study also conducted several interviews with software and hardware engineers of Taiwanese smartphone manufacturers. It was then confirmed that the scope of support of Qualcomm's and Mediatek's toolkits were similar in 2014.

As shown in Table 1, compared with Qualcomm's toolkit, Mediatek's toolkit has more validated components in the module libraries. In other words, when using Mediatek's toolkit, Android smartphone manufacturers can carry out component sourcing, driver porting, quality testing, and so on within a short time. Moreover, in the Mediatek's toolkit, designers of Android manufacturers can select and implement pre-defined logic circuits and reference components in PCB (Printed Circuit Board), which are

Table 1. The scope of support of Qualcomm's and Mediatek's toolkits

\begin{tabular}{|c|c|c|}
\hline & b) Module Libraries & c) Solution Space \\
\hline Qualcomm's Toolkit & $\begin{array}{l}\text { 1) The following peripheral components } \\
\text { are recommended based on past } \\
\text { experiences ofQualcomm's engineers: } \\
\text { - DRAM, LCD, touch panel, sensors, } \\
\text { camera. } \\
\text { 2) The following in-house components are } \\
\text { recommended: } \\
\text { - USB controller, Power Management, } \\
\text { Wifi/BT module. }\end{array}$ & $\begin{array}{l}\text { 1) Qualcomm's MTP(Modem Test } \\
\text { Platform) is not verified by Google's } \\
\text { quality assurance tests (CTS and } \\
\text { Monkey test). } \\
\text { 2) Designers should implement the } \\
\text { layout of PCB by themselves, in } \\
\text { particular in the RF part. }\end{array}$ \\
\hline Mediatek's Toolkit & $\begin{array}{l}\text { 1) The following peripheral components } \\
\text { are verified by Mediatek's quality } \\
\text { assurance (all are ready to use): } \\
\text { - DRAM, USB controller, Power } \\
\text { Management, Wifi/BT module, LCD, } \\
\text { Touch Panel, Sensors, Camera. }\end{array}$ & $\begin{array}{l}\text { 1) Mediatek's FFRD (Form Factor } \\
\text { Reference Design) is verified using } \\
\text { Google's quality assurance tests } \\
\text { (CTS and Monkey test). } \\
\text { 2) Designers can implement PCB } \\
\text { layout (including the RF parts) with } \\
\text { some references of implementation. }\end{array}$ \\
\hline $\begin{array}{l}\text { Comparison of Qualcomm's } \\
\text { and Mediatek's Toolkits }\end{array}$ & $\begin{array}{l}\text { i) Designers can select more validated } \\
\text { components from a recommended } \\
\text { component vendor list. } \\
\text { ii) Designers take more time to find proper } \\
\text { components for their use when using } \\
\text { Qualcomm's chip set and toolkit. }\end{array}$ & $\begin{array}{l}\text { i) The references of implementations } \\
\text { (components, layout, etc.) are } \\
\text { validated already when using } \\
\text { Mediatek's toolkit. } \\
\text { ii) Designers can mix and match from } \\
\text { references to implement PCB layouts } \\
\text { when using Mediatek's toolkit. }\end{array}$ \\
\hline
\end{tabular}

Source: Author's interviews 
also based on Mediatek's validations in advance. Therefore, compared with Qualcomm's toolkit, the solution space of the Mediatek toolkit is better prepared, which also allows designers to mix-and-match for their implementations in PCB. On the other hand, when using Qualcomm's toolkit, designers should take more time to add and subtract components in PCB and optimize the performance of Android smartphones using their own knowledge.

Beginning in the latter half of the 1990s, Qualcomm started supplying IC chipsets to Samsung and other major feature phone manufacturers. In contrast, Mediatek, a late entrant to the semiconductor industry, provided IC chipsets to Chinese feature phone manufacturers since 2004. Compared with Samsung and other major feature phone manufacturers, Chinese feature phone manufacturers did not have sufficient capabilities to develop their products. Therefore, Mediatek broadened the scope of support of their toolkit to make product development easier for Chinese feature phone manufacturers. In doing so, feature phones became more modular (Yoshimoto, 2009), which would take less time for Chinese feature phone manufacturers to develop. Moreover, since releasing smartphone IC chipsets in 2009, Mediatek also expanded the scope of support of their toolkit to a greater extent than Qualcomm for those Chinese smartphone manufacturers.

Samsung uses both their own IC chipsets and those from other semiconductor suppliers; new entrants Vivo and OPPO do not have their own and exclusively use IC chipsets from Qualcomm and Mediatek. Huawei has begun to use their own IC chipsets in addition to those from Qualcomm and Mediatek to get ahead of Samsung. Huawei, Vivo, and OPPO, all with less capabilities to develop Android smartphones as compared with Samsung, tended to use Mediatek's IC chipsets because they can utilize the technical support from Mediatek's toolkit more than the Qualcomm one. In contrast, Qualcomm users have superior product development 
capabilities. When using Mediatek's IC chipsets in their Android smartphone development, they do not even employ the broader scope of support of Mediatek's toolkit.

\section{Concluding Remarks}

von Hippel emphasized that "sticky information" (von Hippel, 1994) exists between users and firms in a series of studies ranging from "lead user (von Hippel, 1986)" to "democratic innovation (von Hippel, 2009)." He asserts that this sticky information can be alleviated with toolkits.

However, this study further emphasizes that toolkits must fit the capabilities of users. 8 For example, the survey of PC games by Jeppesen (2005) noted that users need the ability to fully use the toolkit. Also, Prügl and Schreier (2006) discovered that it was better for PC game lead users to develop toolkits on their own than to use the firms' toolkits. Moreover, Franke, Keinz, and Schreier (2008) investigated ski tools and showed that toolkits with a high level of design freedom was difficult for beginners. The research of Wang and Li (2013) on SNS blogs (the case of Tencent's QQ in China) has shown that toolkits have a moderating effect between user knowledge and the efficiency of innovation.

In 2010, Qualcomm has actually been working on providing IC chipsets to Chinese Android smartphone manufacturers. By collaborating with Chinese mobile phone design house Thundersoft, ${ }^{9}$

8 In addition, it has been noted that toolkits must satisfy users. For example, Franke and von Hippel (2003) and Franke and Piller (2004) showed that toolkits increased user satisfaction in innovations of open source software (i.e., Apache) and watches (i.e., Swatch). In addition, in research on T-shirts by Franke, Schreier, and Kaiser (2010) and smartphone applications by Bergvall-Kåreborn, Björn, and Chincholle (2011), it was shown that toolkits contribute to feelings of achievement and motivation among users.

9 https://store.thundersoft.com/index.php?main_page=index\&cPath=55 
from 2011, Qualcomm started to expand the scope of support of their toolkit to fit the capabilities of Chinese Android smartphone manufacturers. Qualcomm and Thundersoft set up laboratories to validate peripheral components of third party vendors to increase the number of the module libraries. In addition, they created form factor reference designs like Mediatek did, which means their toolkit is not just a big size board for evaluation. Qualcomm attempted to provide more possibilities for designers of Android smartphone manufacturers to perform mix-and-match experiments based on practical considerations. In this sense, the solution space of their toolkit is increasing.

\section{Acknowledgments}

This work was supported by JSPS Grant-in-Aid for Publication of Scientific Research Results, Grant Number JP16HP2004.

\section{References}

Alcacer, J., \& Oxley, J. (2014). Learning by supplying. Strategic Management Journal, 35, 204-223.

Bergvall-Kåreborn, B., Björn, M., \& Chincholle, D. (2011). Motivational profiles of toolkit users: iPhone and Android developers. International Journal of Technology Marketing, 6(1), 36-56.

Franke, N., Keinz, P., \& Schreier, M. (2008). Complementing mass customization toolkits with user communities: How peer input improves customer self-design. Journal of Product Innovation Management, 25, 546-559.

Franke, N., \& Piller, F. T. (2003). Key research issues in user interaction with user toolkits in a mass customisation system. International Journal of Technology Management, 26(5-6), 578-599.

Franke, N., \& Piller, F. (2004). Value creation by toolkits for user 
innovation and design: The case of watch market. Journal of Product Innovation Management, 21, 401-415.

Franke, N., Schreier, M., \& Kaiser, U. (2010). The "I designed it myself" effect in mass customization. Management Science, 56(1), 125-140.

Franke, N., \& von Hippel, E. (2003). Satisfying heterogeneous user needs via innovation toolkits: The case of Apache security software. Research Policy, 32, 1199-1215.

Jeppesen, L. B. (2005). User toolkits for innovation: Consumers support each other. Journal of Product Innovation Management, 22(4), 347-362.

Lee, K. (2005). Making a technological catch up: Barriers and opportunities. Asian Journal of Technology Innovation, 13(2), 97-131.

Min, S. (2016). Adverse user innovation: The case of a semiconductor equipment manufacturer. Annals of Business Administrative Science, 15, 265-272. doi: 10.7880/abas.0161109a

$\mathrm{Mu}$, Q., \& Lee, K. (2005). Knowledge diffusion, market segmentation and technological catch-up: The case of the telecommunication industry in China. Research Policy, 34(6), 759-783.

Prügl, R., \& Schreier, M. (2006). Learning from leading-edge customers at The Sims: Opening up the innovation process using toolkits. $R \& D$ Management, 36(3), 237-250.

Shiu, J.-M. (2016, November). The knowledge acquisition and decision making rights in interfirm division of labor. Paper presented at ABAS Conference 2016 Autumn, University of Tokyo, Japan.

Shiu, J.-M., \& Yasumoto, M. (2016). Benefitting from contributions to the Android open source community. Annals of Business Administrative Science, 15, 239-250. doi: 10.7880/abas.0160825a

Thomke, S., \& von Hippel, E. (2002). Customers as innovators: A new way to create value. Harvard Business Review, 80(4), 74-81.

von Hippel, E. (1986). Lead user: A source of novel product concepts. Management Science, 32(7), 791-805.

von Hippel, E. (1994). Sticky information and the locus of problem solving: Implications for innovation. Management Science, 40(4), 429-439.

von Hippel, E. (2001). User toolkits for innovation. Journal of Product Innovation Management, 18(4), 247-257. 
von Hippel, E. (2009). Democratizing innovation: The evolving phenomenon of user innovation. International Journal of Innovation Science, 1(1), 29-40.

Wang, Y., \& Li, D. (2013). Testing the moderating effects of toolkits and user communities in personalization: The case of social networking service. Decision Support Systems, 55, 31-42.

Weber, C. (2002). Knowledge transfer and the limits to profitability: An empirical study of problem-solving practices in semiconductor manufacturing and process development. IEEE Transactions on Semiconductor Manufacturing, 15(4), 420-426.

Yasumoto, M., \& Shiu, J.-M. (2007). An investigation into collaborative novel technology adoption in vertical disintegration: Interfirm development processes for system integration in the Japanese, Taiwanese, and Chinese mobile phone handset industries. Annals of Business Administrative Science, 6, 35-69. doi: 10.7880/abas.6.35

Yoshimoto, T. (2009). Modularization, design optimization, and design rationalization. Annals of Business Administrative Science, 8, 75-90. doi: 10.7880/abas.8.75 